\title{
ESTRESSE HÍDRICO E REGULADORES DE CRESCIMENTO NA GERMINAÇÃO DE SEMENTES DE CANAFÍSTULA ${ }^{1}$
}

\author{
Beatriz Amoroso Botelho ${ }^{2,4}$; Sonia Cristina Juliano Gualtieri de Andrade Perez ${ }^{3,5^{*}}$ \\ ${ }^{2}$ Pós-Graduanda do Depto. de Botânica - UFSCar. \\ ${ }^{3}$ Depto. de Botânica - UFSCar - Rod. Washington Luiz, Km 235. C.P. 676 - CEP: 13565-905 - São Carlos, SP. \\ ${ }_{5}^{4}$ Bolsista CAPES. \\ ${ }^{5}$ Bolsista CNPq. \\ ${ }^{*}$ Autor correspondente <dscp@power.ufscar.br>
}

RESUMO: Sementes selecionadas escarificadas de canafístula foram submetidas a estresses hídricos simulados, sob $27^{\circ} \mathrm{C}$, com ou sem a adição de poliaminas e giberelina. Os valores de porcentagem e velocidade de germinação obtidos com os testes realizados indicaram que as sementes são resistentes ao estresse hídrico, e a adição de putrescina e espermidina nas concentrações de 5 e 10mM aumenta a performance sob estresse hídrico. O uso de giberelina permite a ampliação do limite máximo de tolerância ao estresse hídrico. Palavras-chave: Peltophorum dubium, PEG 6000, espermidina, giberelina, putrescina

\section{GROWTH REGULATORS AND WATER STRESS IN CANAFISTULA SEED GERMINATION}

\begin{abstract}
Scarified selected seeds of the wood tree species 'canafístula' were submitted to water stress at $27^{\circ} \mathrm{C}$, with and without addition of putrescine and spermidine at concentrations of 5 and $10 \mathrm{mM}$ and gibberellin $0.1 \mathrm{mM}$. The values of rate and germination percentage of all the experiments indicated that the seeds are resistant to water stress. When putrescine and spermidine were added to the germination media the performance under stress increased significantly. Gibberellin extended the maximal tolerance limit to water stress.

Key words: Peltophorum dubium, PEG6000, gibberelin, spermidine, putrescine
\end{abstract}

\section{INTRODUÇÃO}

Peltophorum dubium Spreng (Taubert) (canafístula) pertence à família Fabaceae sub família Mimosoidae. É uma espécie vegetal decídua, heliófita, pioneira, característica da floresta latifoliada semidecídua da Bacia do Paraná, ocorrendo preferencialmente em solos argilosos, úmidos e profundos de beira de rios, tanto na floresta primária densa como em formações secundárias. Apresenta dispersão ampla e abundante, principalmente nas áreas próximas ao grande rio. A madeira é empregada na construção civil, marcenaria, tanoaria, carrocerias, dormentes, serviços de torno, etc. A árvore é ornamental, proporciona ótima sombra quando isolada, podendo ser empregada com sucesso no paisagismo. Como planta rústica e de rápido crescimento, é adequada para a composição de reflorestamentos mistos de áreas degradadas de preservação permanente (Lorenzi, 1992).

A água é o fator iniciante da germinação e está envolvida direta e indiretamente em todas as demais etapas do metabolismo germinativo. Sua participação é decisiva nas reações enzimáticas, na solubilização e transporte de metabólitos, como reagente na digestão hidrolítica de tecidos de reserva da semente. Potenciais osmóticos muito negativos atrasam e diminuem a porcentagem de germinação. O grau mínimo de umidade a ser atingido pela semente para que a germinação ocorra, depende de sua composição química e da permeabilidade do tegumento. (Bradford, 1995).

Em condições de laboratório, são realizados estudos utilizando soluções aquosas de com diferentes potenciais osmóticos para umedecer o substrato de germinação, procurando simular as condições de de estresse hídrico no solo (Hardegree \& Emmerich, 1994). O polietileno glicol é um agente osmótico utilizado nesses estudos; é quimicamente inertes, atóxico para as sementes, simula a seca e não penetra no tegumento devido ao tamanho de suas moléculas (Villela et al., 1991).

Os reguladores de crescimento, que controlam o metabolismo e as respostas das sementes ao ambiente, são fatores intrínsecos que controlam a germinação. Essas substâncias, mediadoras dos processos fisiológicos da germinação, transformam sinais ambientais específicos em respostas bioquímicas, produzindo modificações no estado fisiológico da semente, através da transcrição diferencial, repressão ou desrepressão gênica ou ativação do RNA mensageiro ou, ainda, por alteração da permeabilidade da membrana. Modificações nas propriedades físicas das membranas afetam diretamente a taxa de hidratação, liberação de enzimas, transporte iônico, pH e conteúdo de inibidores, situações estas que interferem na germinação das sementes (Davies, 1994).

Entre os reguladores de crescimento encontramse as poliaminas (putrescina, espermina e espermidina) 
Botelho et al.

envolvidas em processos celulares e sub celulares. São importantes moduladores de processos biológicos como a divisão celular, as respostas ao estresse e o desenvolvimento (Koetje et al., 1993).

Poliaminas são compostos nitrogenados alifáticos policatiônicos e, em plantas, estão relacionados biossinteticamente aos aminoácidos básicos arginina e ornitina e, portanto, ao ácido glutâmico, um componente intermediário no metabolismo do nitrogênio. Em alguns sistemas biológicos, as poliaminas parecem servir como fontes de nitrogênio e, além disso, na forma de substâncias livres, podem se ligar a componentes de baixo (ácido cinâmico) e alto (proteínas e ácidos nucléicos) peso molecular. Com respeito ao mecanismo de ação, as poliaminas podem interagir com membranas celulares, eliminar radicais livres e alterar a expressão gênica (Matilla, 1996). O conteúdo e a concentração de poliaminas, em sementes maduras, varia de acordo com a espécie, havendo uma distribuição entre os orgãos de reserva (cotilédones e endosperma) e eixo embrionário; evidências indicam que o conteúdo de poliaminas aumenta durante os estágios iniciais de germinação (Matilla, 1996).

Villanueva \& Huang (1993) relatam que, durante o período de quebra de dormência tardio e no início do processo de embebição, as concentrações de poliaminas aumentam e ficam semelhantes às de RNA, DNA e proteínas, sugerindo que as poliaminas estejam envolvidas nos estádios iniciais da germinação e sejam essenciais ao processo. Smith (1985) afirma que as poliaminas interagem com grupos amiônicos em membranas, prevenindo o extravazamento celular e promovendo estabilização em condições de estresse. As funções fisiológicas das poliaminas, embora não estejam devidamente esclarecidas, sua ocorrência em altas concentrações nos tecidos em crescimento rápido, sugere a participação na proliferação e desenvolvimento de células. Adicionalmente, as flutuações registradas em seu conteúdo, em resposta à ação de outros fitormônios, têm indicado a possibilidade de atuarem como mensageiras secundárias capazes de mediar os efeitos dos hormônios (Valle et al., 1989).

Segundo Sinska \& Lewandoska (1991) as poliaminas exógenas afetaram a germinação de sementes de maçã (Malus domestica) de modo variável segundo o tipo e a concentração da poliamina e o estado de dormência do embrião. A putrescina e a espermidina estimularam a germinação, e a espermina inibiu o processo, favorecendo a manutenção da dormência por diminuir a produção de etileno. Putrescina e a espermidina participarm da remoção da dormência, independentemente do etileno. Esses autores verificaram que alguns dos efeitos fisiológicos das poliaminas, opostos aos do etileno, podem ser devidos à competição por um precursor comum, a Sadenosilmetionina, à inibição de etileno pelas poliaminas ou a inibição da biossíntese de poliaminas pelo etileno.

As giberelinas constituem uma classe de substâncias reguladoras de crescimento que estimulam a germinação, o crescimento por elongação, entre outras funções. Dentre as várias giberelinas, o $\mathrm{GA}_{3}$ disponível comercialmente, e tem sido muito usada em sistemas biológicos (Arteca, 1996).

Altos níveis de giberelinas são encontradas em sementes imaturas. Várias pesquisas independentes mostraram que 0 ácido giberélico estimula a $\alpha$ - amilase e outras enzimas proteolíticas, promovendo a hidrólise do material de reserva. As giberelinas promovem o crescimento pelo aumento da plasticidade da parede celular seguida pela hidrólise do amido em açúcar, que reduz o potencial hídrico na célula, resultando na entrada de água no seu interior e, promovendo o alongamento, sendo que os passos básicos envolvidos nesse mecanismo são: o $\mathrm{GA}_{3}$, produzido no embrião é transferido para camada de aleuroma das células onde a $\alpha$-amilase é produzida via síntese de novo e essa promove a conversão do amido em açúcar, que é usado então para o crescimento da plântula (Arteca, 1996).

Ni \& Bradford (1993) demonstraram através de sementes de tomate mutante com deficiência de GA, que as giberelinas estão envolvidas na iniciação da germinação. Na presença de giberelina exógena do tipo $\mathrm{GA}_{4+7}$ a germinação dessas sementes foi quantitativamente estimulada, tanto em relação à germinablidade quanto à velocidade. Nas sementes deficientes em ABA, a presencá de GA resultou em aumentos da velocidade germinação e maior tolerância à potenciais hídricos reduzidos.

Assim, quando se analisa o desempenho das sementes sob algum tipo de estresses ambiental, a presença de reguladores de crescimento deve ser considerada, devido sua interferência na germinabilidade.

Devido à escassez de estudos sobre a fisiologia e ecologia de Peltophorum dubium, o presente trabalho teve como objetivo de avaliar a resistência ao estresse hídrico durante a germinação e a participação poliaminas e giberelinas nessa situação.

\section{MATERIAL E MÉTODOS}

Os experimentos foram realizados no laboratório de Ecofisiologia de Sementes do Departamento de Botânica da UFSCar. Foram utilizadas sementes de canafístula, provenientes do IPEF (Instituto de Pesquisas e Estudos Florestais - Piracicaba).

As sementes de canafístula, visivelmente consideradas em melhor estado de conservação, foram manulamente selecionadas e submetidas a pré tratamento de imersão em ácido sulfúrico comercial (98\%) por 20 minutos (Perez et al., 1999). Em seqüência, foram lavadas em água corrente e, em água destilada. Posteriormente, após secagem em papel de filtro, foram distribuídas em placas de Petri $(9 \mathrm{~cm}$ de diâmetro) esterilizadas a $150^{\circ} \mathrm{C}$, e forradas internamente com papel de filtro esterilizado e umedecido com $6 \mathrm{ml}$ de diferentes soluções (Estudos 1, 2 e 3) que sempre continham Captan $(0,2 \%)$, com o intuito de dificultar o desenvolvimento de fungos (Clarck \& Scott, 1982). O papel de filtro e a solução 
- teste foram substituídos sempre que necessário. Em seqüência, as placas foram seladas com filme de PVC para prevenir a evaporação e colocadas em câmara, sob $27^{\circ} \mathrm{C}$ (Perez et al., 1998). A cada período de 24 horas as sementes germinadas foram retiradas e contadas para as estimativas da porcentagem e velocidade de germinação. Foram consideradas como germinadas as sementes que originaram plântulas com raízes medindo, no mínimo, dois milímetros de comprimento (Brasil, 1992); as contagens foram encerradas quando as sementes remanescentes nas placas apresentavam-se mortas.

Estudo 1 (Estresse hídrico): Foram empregadas diferentes soluções aquosas de PEG 6.000 para simular défices hídricos, utilizando - se as concentrações indicadas em Vilella et al. (1991). As sementes foram colocadas para germinar em soluções de PEG $6.000 \mathrm{com}$ os seguintes potenciais osmóticos: $0.0 ;-0.2 ;-0.4 ;-0.6$; $0.8 ;-1.0 ;-1,2$ e $-1,4 \mathrm{MPa}$, sob temperatura ótima $\left(27^{\circ} \mathrm{C}\right)$.

Estudo 2 (Estresse hídrico na presença de poliaminas): Foram adicionadas putrescina e espermidina nas concentrações de 5 e $10 \mathrm{mM}$ nas soluções de PEG 6000 (Estudo 1), com potenciais osmóticos situados entre 0,0 e -1,0MPa.

Estudo 3 (Estresse hídrico na presença de giberelinas): Foi adicionado $\mathrm{GA}_{3}$ a $0,1 \mathrm{mM}$ nas soluções de PEG 6000 (Estudo 1), com potenciais osmóticos situados entre 0,0 e $-1,0 \mathrm{MPa}$.

Os dados da germinabilidade $(\mathrm{G})$, do tempo médio (t) e velocidade de germinação(v) foram obtidos através da aplicação das seguintes equações, citadas em Labouriau (1983):

$\mathrm{G}=(\mathrm{N} / \mathrm{A}) \times 100$, onde: $\mathrm{N}=$ número de sementes germinadas e $A=$ número total de sementes colocadas para germinar

\section{$v=1 / t$, onde: $t$ = tempo médio de germinação}

Planejamento experimental: Foram utilizadas quatro repetições de 50 sementes, em esquema inteiramente casualizado, para os diferentes reguladores de crescimento. Os valores de porcentagem, anteriormente à análise de variância (uma ou duas entradas), foram transformados em arc sen $\sqrt{ } \%$. As médias foram contrastadas pelo teste de Tukey (Spiegel, 1978).

\section{RESULTADOS E DISCUSSÃO}

Apesar da canafístula ser encontrada principalmente em solos argilosos, úmidos e profundos, em beiras de rios, suas sementes são bastante resistentes ao estresse hídrico simulado, com limite de tolerância entre $-1,4$ e -1,6MPa. Observou - se, em geral, decréscimos na porcentagem e na velocidade de germinação à medida que 0 estresse hídrico foi sendo ampliado (Estudo 1). O parâmetro velocidade foi o primeiro a apresentar decréscimo nos valores. O teste de Tuckey revelou diferenças significativas entre as médias na velocidade de germinação entre os potenciais 0,0 e - $0,2 \mathrm{MPa}$, enquanto que para os potenciais variando desde $-0,4$ até $-1,4 \mathrm{MPa}$ não houve diferenças entre eles (TABELAS 1 e 2).

Em relação à germinabilidade, não houve diferenças entre o grupo controle e os potenciais de $-0,2$ e $-0,4 \mathrm{MPa}$. Porém, entre os potenciais situados entre -0,6 e -1,6MP foi registrada diferença entre todos eles (TABELA 1).

Pelas afirmações de Heydecker (1977), o aumento do estresse ambiental, em geral, leva inicialmente a um decréscimo na velocidade de germinação e só posteriormente vem afetar a porcentagem de germinação das sementes. Ainda de acordo com esse autor, o que é sentido como estresse, não depende somente da constituição genética mas também da condição fisiológica de uma semente.

De acordo com Bewley \& Black (1994) o estresse hídrico pode reduzir tanto a porcentagem quanto a velocidade de germinação, com uma grande variação de respostas entre as espécies, desde aquelas muito sensíveis até as mais resistentes. Sementes resistentes possuem a vantagem ecológica de estabelecer plântulas em áreas onde sementes sensíveis à seca não podem fazê-lo.

TABELA 1 - Valores médios da porcentagem de germinação para sementes de canafístula sob estresse hídrico, com ou sem a adição de reguladores (Put = putrescina; Esperm = espermidina).

\begin{tabular}{|c|c|c|c|c|c|c|c|c|c|c|c|}
\hline \multirow[t]{2}{*}{ Estudo } & \multirow{2}{*}{\multicolumn{2}{|c|}{$\begin{array}{l}\text { Reguladores } \\
(\mathrm{mM})\end{array}$}} & \multicolumn{9}{|c|}{ Potenciais osmóticos (MPa) } \\
\hline & & & $-0,0$ & $-0,2$ & $-0,4$ & $-0,6$ & $-0,8$ & $-1,0$ & $-1,2$ & $-1,4$ & $-1,6$ \\
\hline & & & \multicolumn{9}{|c|}{ o, o de germinação - } \\
\hline 1 & Ausente & & $97,5 a$ & $94,5 \mathrm{a}$ & $93,5 \mathrm{a}$ & $89,0 \mathrm{~b}$ & $67,0 \mathrm{~b}$ & $60,5 d$ & $20,1 \mathrm{e}$ & $3,0 f$ & $0,0 \mathrm{~g}$ \\
\hline \multirow[t]{6}{*}{2} & Put & $(0,0)$ & $97,5 \mathrm{Aa}$ & $94,5 \mathrm{Aa}$ & $93,5 \mathrm{Aa}$ & $89,0 \mathrm{Bb}$ & $67,0 \mathrm{Bc}$ & $60,5 \mathrm{Bd}$ & 20,1 e & $3,0 \mathrm{f}$ & $0,0 \mathrm{~g}$ \\
\hline & & $(0,5)$ & $90,5 \mathrm{Aa}$ & $96,5 \mathrm{Aa}$ & $98,5 \mathrm{Aa}$ & $94,5 \mathrm{Aa}$ & $97,5 \mathrm{Aa}$ & $97,0 \mathrm{Aa}$ & - & - & - \\
\hline & & $(1,0)$ & $88,5 \mathrm{Bb}$ & $99,0 \mathrm{Aa}$ & $97,0 \mathrm{Aa}$ & $96,5 \mathrm{Aa}$ & $98,5 \mathrm{Aa}$ & $99,5 \mathrm{Aa}$ & - & - & - \\
\hline & Esperm & $(0,0)$ & $97,5 \mathrm{Aa}$ & $94,5 \mathrm{Aa}$ & $93,5 \mathrm{Aa}$ & $89,0 \mathrm{Bb}$ & $67,0 \mathrm{Bc}$ & $60,5 \mathrm{Bd}$ & $20,1 \mathrm{e}$ & $3,0 \mathrm{f}$ & $0,0 \mathrm{~g}$ \\
\hline & & $(0,5)$ & $98,5 \mathrm{Aa}$ & $98,0 \mathrm{Aa}$ & $98,5 \mathrm{Aa}$ & $99,0 \mathrm{Aa}$ & $97,0 \mathrm{Aa}$ & $94,5 \mathrm{Aa}$ & - & - & - \\
\hline & & $(1,0)$ & $96,5 \mathrm{Aa}$ & $89,0 \mathrm{Ab}$ & $98,0 \mathrm{Aa}$ & $97,5 \mathrm{Aa}$ & $94,0 \mathrm{Aa}$ & $94,5 \mathrm{Aa}$ & - & - & - \\
\hline \multirow[t]{2}{*}{3} & GA3 & $(0,0)$ & $97,5 \mathrm{Aa}$ & $94,5 \mathrm{Aa}$ & $93,5 \mathrm{Aa}$ & $89,0 \mathrm{Ab}$ & $60,5 \mathrm{Ac}$ & $20,1 \mathrm{Bd}$ & 3,0 Be & $0,0 \mathrm{f}$ & \\
\hline & GA3 & $(0,1)$ & $96,0 \mathrm{Aa}$ & $94,0 \mathrm{Aa}$ & $92,0 \mathrm{Aa}$ & $73,5 \mathrm{Bb}$ & $68,0 \mathrm{Bc}$ & $62,5 \mathrm{Ac}$ & $41,5 \mathrm{Ad}$ & $12,5 \mathrm{e}$ & $4,5 f$ \\
\hline
\end{tabular}

Dentro de cada regulador, médias seguidas pela mesma letra (maiúscula nas colunas e minúsculas na linhas) não diferem a $5 \%$. 
TABELA 2 - Valores médios de velocidade (V) de germinação para sementes de canafístula sob estresse hídrico, com ou sem a adição de reguladores (Put = putrescina; Esperm = espermidina).

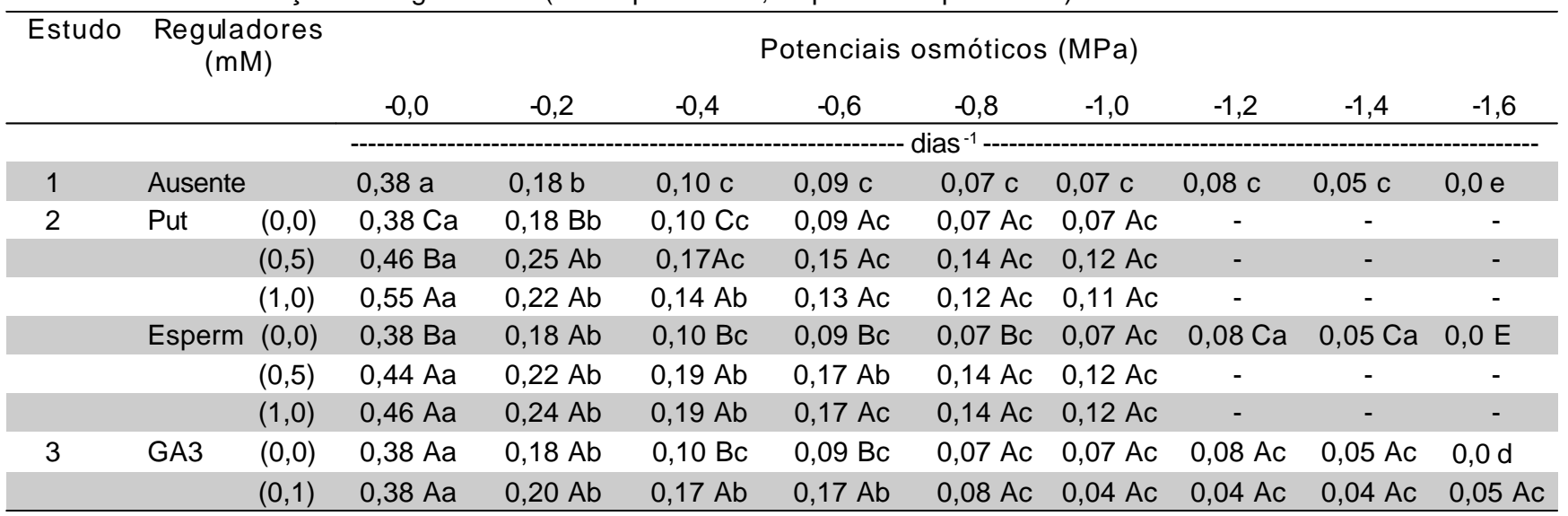

Dentro de cada regulador, médias seguidas pela mesma letra ( maiúscula nas colunas e minúsculas na linhas) não diferem a $(P<0,05)$

Neste estudo, verificou-se que sementes de canafístula possuem um elevado limite de tolerância à seca, situado entre $-1,4$ e $-1,6 \mathrm{MPa}$. Dentro da família Fabaceae, pode-se citar como exemplo o limite de tolerância à seca de outras espécies: Dimorphandra mollis entre -0,6 e -0,8MPa (Zpevak, 1994); Stryphnodendron pollyphyllum entre - 0,6 e - 0,8MPa (Tambelini, 1994); Anadenanthera pavonina entre $-0,6$ e $-0,7 \mathrm{MPa}$ (Fanti \& Perez, 1998); Pterogyne nitens entre - 1,0 e -1,2MPa (Nassif \& Perez, 1997); Enterolobium contortisiliquum entre - 1,6 e - 1,8MPa (Hebling, 1997), Prosopis juliflora entre - 1,4 e -1,6MPa (Perez \& Nassif, 1998); Cassia excelsa entre - 0,6 e - 0,7MPa (Jeller, 1997); Plathymenia reticulata entre $-1,0$ e $-1,2 \mathrm{MPa}$ (Miranda, 1999).

Quando a putrescina foi adicionada ao meio germinativo (Estudo 2) foi observada uma atenuação parcial do estresse hídrico, com aumento nos valores de porcentagem e velocidade de germinação, mas não no limite máximo de tolerância. Para a porcentagem de germinação, verificou - se um aumento significativo dos valores a partir $-0,8 \mathrm{MPa}$, em relação ao controle. Não foi verificado diferença estatística entre os potenciais de $-0,8$ e $-1,0 \mathrm{MPa}$. A adição de putrescina $10 \mathrm{mM}$ reduziu significativamente a porcentagem de germinação do grupo controle, em relação aos demais potenciais omóticos (TABELA 1).

Para a velocidade de germinação a adição de putrescina $5 \mathrm{mM}$ provocou aumentos nos valores, em relação ao grupo controle, nos potenciais 0,$0 ;-0,4 \mathrm{e}$ $-0,8 \mathrm{MPa}$. A adição de putrescina $10 \mathrm{mM}$ aumentou os valores de velocidade, em relação ao grupo controle, apenas no potencial de $0,0 \mathrm{MPa}$ (TABELA 2).

Quando se adicionou uma outra poliamina, a espermidina, no meio germinativo (Estudo 2), também foi observado um aumento da performance sob estresse hídrico mais severo. Houve um aumento significativo na germinabilidade, a partir de $-0.8 \mathrm{MPa}$, em ambas concentrações utilizadas. Não se verificou diferenças entre os potenciais $-0,8$ e $-1,0 \mathrm{MPa}$ e nem entre as duas concentrações de espermidina, com relação aos aumentos produzidos. No potencial de $-0,2 \mathrm{MPa}$ observou-se uma diminuição dos valores de porcentagem, com o uso de espermidina $10 \mathrm{mM}$, em relação às sementes que não 0 regulador (TABELA 1).

Foi registrado um aumento dos valores, em vários potenciais, em relação ao controle, que não recebeu o hormônio (TABELA 2). Não houve diferença significativa em relação às duas concentrações empregadas.

No grupo controle, foi a espermidina $(5 \mathrm{mM})$ que promoveu uma maior porcentagem de germinação enquanto que a maior velocidade de germinação foi observada com a aplicação de putrescina $(10 \mathrm{mM})$.

No potencial osmótico de $-0.2 \mathrm{MPa}$ a maior porcentagem de germinação foi observada com a aplicação de putrescina à $10 \mathrm{mM}$ e este mesmo regulador à $5 \mathrm{mM}$ ocasionou a maior velocidade de germinação.

No potencial hídrico com valor de $-0.4 \mathrm{MPa}$, tanto a putrescina à $5 \mathrm{mM}$ como a espermidina à $5 \mathrm{mM}$ promoveram a maior porcentagem de germinação enquanto que a maior velocidade de germinação foi observada com a aplicação de espermidina em ambas as concentrações.

$\mathrm{Na}$ concentração de $-0.6 \mathrm{MPa}$, a maior velocidade de germinação foi observada com aplicação de espermidina em ambas as concentrações e a maior porcentagem de germinação foi promovida pela espermidina à $5 \mathrm{mM}$.

O potencial osmótico com valor de $-0.8 \mathrm{MPa}$, putrescina à $5 \mathrm{mM}$ e espermidina à $5 \mathrm{e} 10 \mathrm{mM}$ ocasionaram a maior velocidade de germinação, enquanto que putrescina à $10 \mathrm{mM}$ promoveu a maior porcentagem de germinação.

Em soluções de $-1.0 \mathrm{MPa}$, a maior velocidade de germinação foi observada com a aplicação de putrescina à $5 \mathrm{mM}$ e espermidina em ambas as concentrações. A maior porcentagem de germinação foi devido à adição de putrescina à $10 \mathrm{mM}$. 
A espermidina à $5 \mathrm{mM}$ apareceu num maior número de potenciais hídricos testados ocasionando as maiores porcentagens de germinação (concentrações de $-0.2,-0.8$ e $-1.0 \mathrm{MPa}$ ). $\mathrm{O}$ uso de espermidina à $10 \mathrm{mM}$ promoveu as maiores velocidades de germinação num maior número de potenciais osmóticos testados (concentrações de $-0.4,-0.6,-0.8,-1.0 \mathrm{MPa}$ ). Então foi a espermidina à $5 \mathrm{mM}$ que provocou, em média, a maior porcentagem de germinação e este mesmo horrmônio à $10 \mathrm{mM}$ que promoveu, em média, a maior velocidade de germinação

Independente do potencial osmótico, os valores de porcentagem e velocidade de germinação foram sempre mais elevados na presença das poliaminas (TABELA 3).

Kramer (1974) relata que o primeiro efeito mensurável do estresse hídrico é uma diminuição do crescimento, causada pela diminuição da expansão celular. Segundo Wenkert et al., (1978) e Simon (1978) o processo de alongamento celular e a síntese da parede são altamente sensíveis ao déficit hídrico. Bradford (1990) afirma que a redução do crescimento como conseqüência da diminuição do alongamento celular seria causada por um decréscimo na turgescência celular.

Brown \& Khan (1977) afirmaram que o potencial hídrico também afeta os níveis hormonais endógenos, uma vez que a atenuação do estresse foi verificada em muitas espécies quando se fez a adição de hormônios exógenos como as giberelinas ou as citocininas.

De acordo com Valle et al. (1989) a inibição do crescimento do eixo embrionário de grão-de-bico (Cicer arietinum) devido a inibidores da biossíntese de poliaminas sugerem que estão envolvidas neste processo. Esses autores indicaram que a putrescina foi mais eficiente que a espermidina e a espermina em reverter os efeitos dos inibidores sobre o crescimento dos segmentos de embrião e apontam sua importância na elongação celular. Ainda segundo esses mesmos autores é possível que, como as giberelinas, as poliaminas possam estar envolvidas tanto na divisão quanto na elongação celular.

TABELA 3 - Análise conjunta para a porcentagem e velocidade de germinação para sementes de $P$. dubium em diferentes concentrações hormonais (Estudos 1, 2 e 3), independente do potencial osmótico.

\begin{tabular}{lcc}
\hline \multicolumn{1}{c}{ Reguladores } & Germinação & Velocidade \\
\hline & $\%$ & dias $^{-1}$ \\
\hline $0 \mathrm{mM}$ & $69,38 \mathrm{~B}$ & $0,15 \mathrm{C}$ \\
$5 \mathrm{mM}$ putrescina & $79,70 \mathrm{~A}$ & $0,21 \mathrm{~A}$ \\
$10 \mathrm{mM}$ putrescina & $82,23 \mathrm{~A}$ & $0,21 \mathrm{~A}$ \\
$5 \mathrm{mM}$ espermidina & $83,47 \mathrm{~A}$ & $0,19 \mathrm{~B}$ \\
10mM espermidina & $81,05 \mathrm{~A}$ & $0,22 \mathrm{~A}$ \\
$0,1 \mathrm{mM}$ giberelina & $67,50 \mathrm{~B}$ & $0,14 \mathrm{D}$ \\
\hline
\end{tabular}

Médias seguidas pela mesma letra, numa mesma coluna, não diferem a $5 \%$.
Felix \& Harr (1983) observaram que o conteúdo total de poliaminas é maior em sementes embebidas do que em sementes secas. Isso apoia a hipótese de que o acúmulo de putrescina (a poliamina mais abundante) observado no embrião durante a embebição das sementes é devido à sua síntese líquida e, provavelmente, está relacionado às numerosas divisões celulares que ocorrem no início da germinação.

Para Street \& Öpik (1983) o déficit hídrico altera a permeabilidade da membrana e as propriedades do tonoplasto, permitindo a interação entre proteínas citoplasmáticas e enzimas hidrolíticas. Com o aumento do déficit hídrico verifica - se uma redução da armazenagem do ATP, desacoplamento de elétrons na fosforilação oxidadtiva, e danos nas membranas celulares.

Com o valor de $\mathrm{pH}$ do meio celular, as poliaminas podem afetar a síntese e a atividade de macromoléculas, permeabilidade da membrana e processos parciais de miotse e meiose. As poliaminas podem neutralizar as mudanças induzidas por hormônios na permeabilidade da membrana celelular, um dos prováveis alvos das poliaminas (Galston \& KauhrSawhney, 1994).

Através desse estudo, foi possível verificar que as poliaminas levam a uma atenuação do estresse hídrico. Esta atenuação é comprovada devido a aumentos significativos na germinabilidade e velocidade de germinação para as sementes de $P$. dubium, quando comparadas aos valores obtidos sem adição de poliaminas. Esses resultados vêm confirmar as afirmações de Smith (1985), segundo as quais, as poliaminas interagem com grupos amiônicos em membranas, prevenindo o vazamento e causando uma estabilização em condições de estresse.

Galston \& Kaur-Sawhney (1994) afirmaram que as poliaminas são responsáveis por muitos controles fisiológicos como luz, hormônios, injúrias e estresse, e aplicações externas podem afetar importantes processos fisiológicos. Além disso foi verificado que existe interação entre potenciais hídricos e concentrações hormonais, tanto para a germinabilidade como para a velocidade de germinação, uma vez que estes parâmetros se alteram em função das variações entre os diferentes potenciais e as diferentes concentrações de reguladores.

Quando a giberelina a $0,1 \mathrm{mM}$ foi adicionada ao meio germinativo (Estudo 3), verificou-se atenuação parcial do estresse hídrico, que só foi significativo a partir de $-1,2 \mathrm{MPa}$, para a porcentagem. (TABELA 1). Para a velocidade, aumentos significativos só foram registrados nos potenciais $-0,4$ e $-0,6 \mathrm{MP}$. Porém, houve uma ampliação do limite máximo de tolerância ao estresse hídrico para - 1,6MPa, fato não verificado com o uso de poliaminas (TABELA 2).

Hebling (1997) também verificou que as poliaminas foram mais efetivas em atenuar o estresse hídrico que as giberelinas, levando - se em consideração os parâmetros porcentagem e velocidade. 
$\mathrm{Ni} \&$ Bradford (1993) verificaram que o aumento da concentração de $\mathrm{GA}_{3}$ no meio produziu um aumento da germinação e além disto, o processo germinativo se tornou muito menos sensível ao estresse hídrico.

Tanto poliaminas como giberelinas estão envolvidos no processo germinativo, mas as formas de atuação podem ser diferentes. Assim, é provável que a giberelina primeiramente tenha revertido a dormência ocasionada pelo desequilíbrio hormonal induzido pelo PEG, passando então a auxiliar na expansão celular e as poliaminas tenham atuado mais diretamente atenuando o os efeitos deletérios do mesmo, alterando a permeabilidade da membrana, afetando a permeabilidade da membrana e participando dos processos e crescimento do embrião (Davies, 1994).

\section{CONCLUSÕES}

- Houve diminuição na velocidade e porcentagem de germinação com o aumento da intensidade do estresse.

- A putrescina e espermidina nas diferentes concentrações atenuaram parcialmente os efeitos do estresse hídrico.

- $\mathrm{GA}_{3}$ foi menos efetiva que as poliaminas em aumentar a porcentagem e velocidade de germinação.

- $\mathrm{GA}_{3}$ ampliou o limite de tolerância ao estresse hídrico.

\section{AGRADECIMENTOS}

À CAPES pela concessão de bolsa PET à primeira autora e ao CNPq pela concessão de bolsa de pesquisador à segunda autora.

\section{REFERÊNCIAS BIBLIOGRÁFICAS}

ARTECA, R.D. Plant growth substances: principles and applications. New York: Chapman \& Hall, 1996. 332p.

BEWLEY, J.D.; BLACK, M. Seeds: physiology of development and germination. New York: Plenum Press, 1994. 445p.

BRADFORD, K.J. Water relations analysis of seed germination rates. Plant Physiology, v.94, p.840-849, 1990.

BRADFORD, K.J. Water relations in seed germination. In: KIGEL, J.; GALILI, J. Seed development and germination New York: Marcel Dekker, 1995. 853p.

BRASIL. Ministério da Agriculturae Reforma Agrária. Regras para análise de sementes. Brasília: SNDA, DNDV,CLV, 1992. 365p.

BROWN, J.W.; KHAN, A.A. Alleviation of salinity and high temperature stress by plant growth regulators into lettuce seeds via acetona. Journal of the American Society for Horticultural Science, v.10, p.716-721, 1977.

CLARCK, S.M. ; SCOTT, D.J. Effects of carboxin, benomyl and captan on the germination of wheat during the post harvest dormency period. Seed Science and Technology, v.10, p.87-94, 1982.

DAVIES, P.J. Plant hormones: their role in plant growth and development. 2.ed. New York: Nijhoff Publishers, 1994. 678p.

FANTI, S. C.; PEREZ, S.C.J.G. de A. Efeitos do estresse hídrico, salino e térmico no processo germinativo de sementes de Anadenanthera pavonina L. Revista Brasileira de Sementes, v.2, p.167-177, 1998.
FELIX, H.; HARR, J. Association of polyamines to different parts of various plant species. Physiologia Plantarum, v.71, p.245-250, 1983.

GALSTON, A.W.; KAUR-SAWHNEY, R. Polyamines as endogenous growth regulators. In: DAVIES, P.J. Plant hormones: their role in plant growth and development. 2.ed. New York: Nijhoff Publishers, 1994. p.280-295.

HARDEGREE, S.P.; EMMERICH, W.E. Seed germination in response to polyetilene glycol solution. Seed Science and Technology, v.22, p.1-7, 1994.

HEYDECKER, W. Stress and seed gerrination: an agronomic view. In: KHAN, A.A. The phisiology and biochemistry of seed dormancy and germination. New York: North Holland Publishing, 1977. p.237-282.

HEBLING, S.A. Aspectos ecofisiológicos da germinação de sementes de Enterolobium contortisiliquum (Velozo) Morong. São Carlos, 1997. 143p. Tese (Doutorado) - Universidade Federal de São Carlos.

JELLER, $\mathrm{H}$. Efeitos de fatores ambientais e métodos artificias para superação de dromência de sementes de Cassia excelsa Scrhad. São Carlos, 1997. 133p. Dissertação (Mestrado) Universidade Federal de São Carlos.

KOETJE, D.S.; KONONOWICZ, H.; HODGES, T.K. Polyamine metabolism associated with growth and embryogenic potencial of rice. Journal of Plant Physiology, v.141, p.215-220, 1993.

KRAMER, P.J. Fifty years of progress in water relations research. Plant Physiology, v.54, p.463- 471, 1974.

LABOURIAU, L.G. A germinação das sementes. Washington: OEA, 1983. 173p.

LORENZI, H. Árvores brasileiras: manual de identificação e cultivo de plantas arbóreas. Nova Odessa: Editora Plantarum, 1992. 352p.

MATILLA, A.J. Polyamines and seed germination. Seed Science Research, v.6, p.81-93, 1996.

MIRANDA, A.R. Aspectos ecofisiológicos da germinação e conservação de sementes de Plathymenia reticulata Benth. Fabaceae - Mimosoidae. São Carlos, 1999. 188p. Tese (Doutorado) - Universidade Federal de São Carlos.

NASSIF, S.M.L.; PEREZ, S.C.J.G. de A. Germinação de sementes de amendoim do campo (Pterogyne nitens Tul. Fabaceae - Caesalpinoideae) submetidas a diferentes condições de estresse hídrico e salino. Revista Brasileira de Sementes, v.19. p.143-150, 1997.

NI, B.R.; BRADFORD, K.J. Germination and dormancy of abscisic acid and gibberellin - deficient mutant tomato (Lycopersicum esculentum) seeds. Plant Physiology, v.101, p.607-617, 1993.

PEREZ, S.C.J.G. de A.; FANTI, S.C.; CASALI, C.A. Dormancy break and light quality effects on seed germination of Peltophorum dubium (Spreng) Taubert - Canafístula. Revista Árvore, v.5, p.131-137, 1999.

PEREZ, S.C.J.G. DE A.; NASSIF, S.M.L. Efeitos do envelhecimento precoce, polietileno glicol e substratos na viabilidade e vigor de sementes de algarobeira. Pesquisa Agropecuária Brasileira, v.33, p.2055-2064, 1998.

PEREZ, S.C.J.G. DE A.; FANTI, S.C.; CASALI, C.A. Temperature limits and thermal stren on seed germination of Peltophorum dubium Spreng (Taubert). Revista Brasileira de Sementes, v.20, p.134-142, 1998.

SIMON, E.W. Plant membranes under dry conditions. Pesticultural Science, v.9, p.169-173, 1978.

SINSKA, I.; LEWANDOWSKA, U. Polyamines and ethylene in the removal of embryonal dormancy in apple seeds. Physiologia Plantarum, v.81, p.59-64, 1991. 
SMITH, T.A. Polyamines. Annual Review of Plant Physiology, v.36, p.117-143, 1985

SPIEGEL, M.R. Probabilidade e estatística. São Paulo: McGraw-Hill do Brasil, 1978. 178p.

STREET, H.E.; ÖPIK, H. The physiology of flowering plants, their growth and development. Maryland: Edward Arnolds, 1983. 279p.

TAMBELINI, M. Tratamentos pré-germinativos e aspectos ecofisiológicos na germinação de sementes de Stryphnodendron polyphyllum Mart. São Carlos, 1994. 112p. Dissertação (Mestrado) - Universidade Federal de São Carlos.

VALLE, T.; FERNÁNDEZ, J.J.; NICOLÁS, G. Effect of difluoromethylarginine and difluoromethylornithine on seed germination and on epicotyl growth in Cicer arietinum. Plant Physiology and Biochemistry, v.27, p.113-117, 1989.

VILLANUEVA, V.R.; HUANG, H. Effect of polyamine inhibition on pea seed germination. Journal of Plant Physiology, v.141, p.336-340, 1993.
VILLELA, F. A.; FILHO, L.D.; SEQUEIRA, E.L. Tabela de potencial osmótico em função da concentração de polietilenoglicol 6.000 e da temperatutra. Pesquisa Agropécuaria Brasileira, v.26, p.1957-1968, 1991.

WENKERT, W.; LEMON, E.R.; SEQUEIRA, E.L. Leaf elongation and turgor pressure in field, grown soybean. Agronomy Journal, v.70, p.761-764, 1978.

ZPEVÁK, F.A. Efeitos do ácido abscísico, potencial hídrico, temperatura e tratamentos para quebra de dormência na germinação de sementes de Dimophandra mollis Benth. São Carlos, 1994. 173p. Dissertação (Mestrado) - Universidade Federal de São Carlos.

Recebido em 16.02.00 